\title{
Epidemiology of Non-communicable Disease Risk Factors Among Adults Residing in Gilgel Gibe Field Research Centre, Jimma, South West Ethiopia
}

\author{
Tomas Benti Tefera ${ }^{1,}$, , Kifle Woldemichael ${ }^{2}$, Fasil Tessema ${ }^{2}$, Fessahaye Alemseged ${ }^{2}$ \\ ${ }^{1}$ Department of Nursing, Madda walabu University, College of Medicine and Health Sciences, Bale-Goba, Southeast Ethiopia \\ ${ }^{2}$ Department of Epidemiology, Jimma University, College of Health Sciences, Jimma, Southwest Ethiopia
}

\section{Email address:}

thomas_benti@yahoo.com (T. B. Tefera), alazarfasil@yahoo.com (F. Tessema), fessahayeatd@yahoo.com (F. Alemseged)

\section{To cite this article:}

Tomas Benti Tefera, Kifle Woldemichael, Fasil Tessema, Fessaye Alemseged. Epidemiology of Non-communicable Disease Risk Factors Among Adults Residing in Gilgel Gibe Field Research Centre, Jimma, South West Ethiopia. European Journal of Preventive Medicine. Vol. 3, No. 4, 2015, pp. 124-128. doi: 10.11648/j.ejpm.20150304.15

\begin{abstract}
Background: Burden of Chronic non-communicable diseases are increasing rapidly in developing countries and different Risk factors are contributing to the high burden of Non-communicable diseases in developing countries. Tobacco is most common risk factor and responsible for about 4.9 million deaths each year. Alcohol consumption is the leading risk factor for mortality in developing countries. Physical inactivity is also leading causes of non-communicable diseases, including cardiovascular diseases and about 1.9 million deaths are attributed to physical inactivity Worldwide. Hypertension is a growing public health problem. Worldwide, an estimated 1 billion individuals have Hypertension, and approximately 7.1 million deaths per year are attributed to hypertension. This study tried to determine the prevalence of the selected non-communicable disease risk factors among adults at Gilgel Gibe field Research centre of Jimma University, Southwest Ethiopia. Method: - Data were extracted from a population-based survey of chronic Non-communicable Diseases at Gilgel Gibe Field Research Center, southwest Ethiopia which was conducted from September 2008 to January 2009. A data of 4273 individuals were included in the analysis. The Interview was used to collect data on sociodemographic and selected behavioural variables. Blood pressure was taken three times for each individual and the average was taken to classify the individuals to hypertensive or not. Data were analysed using SPSS for windows version 15. Descriptive and analytical analysis was conducted. Statistical significance was declared at $\mathrm{p}<0.05$ at $95 \%$ of CI. The Results: - The prevalence rate of hypertension based on blood pressure measurement was $82(3.2 \%)$. The prevalence of alcohol consumption, low-level physical activity \& smoking was $7.0 \%, 9.0 \%$ and $9.4 \%$ respectively. Conclusion: - The prevalence of NCD Risk factors among the study subjects was high. These findings are crucial for evidence based decision making. This finding will also give baseline information for researchers and other stakeholders to conduct further studies.
\end{abstract}

Keywords: Hypertension, Smoking, Alcohol, High Blood Pressure

\section{Introduction}

Chronic non-communicable diseases are a major contributor to the burden of disease in developed countries and are increasing rapidly in developing countries. Eighty percent of all deaths worldwide that are attributed to chronic diseases are already occurring in developing countries (1).

High blood pressure is an important public health problem worldwide because it is a major modifiable risk factor for coronary heart disease, stroke, and chronic kidney disease. According to the global burden of hypertension study, 26.4\% of an adult population in 2000 had hypertension and the number was predicted to increase in 2025 by $60 \%$ (2). Both lower-income as well as -higher income groups are at increased risk of developing hypertension (3).

Hypertension is one of the most modifiable risk factors for cardiovascular diseases. However, awareness about treatment and control of hypertension is extremely low among developing nations including Ethiopia (4). Recent evidences indicate that hypertension and raised blood pressure are increasing, partly because of the increase in risk factors, including smoking, obesity, and harmful use of alcohol and lack of exercise (4).

Tobacco is the fourth most common risk factor for disease 
and the second major cause of death worldwide \&currently responsible for the death of one in ten adults worldwide (about 4.9 million deaths each year) (5). About 1.3 billion people worldwide smoke, and it is estimated that deaths from tobacco consumption will be about 10 million people per year by 2020 due to increased risk of getting heart disease, stroke (1).

Alcohol consumption is the leading risk factor for disease burden and mortality in low developing countries and the third largest risk factor in developed countries (6). The Proportion of disease burden attributed to alcohol use in the developing world is between $2.6 \%$ to $9.8 \%$ of the total burden for males and $0.5 \%$ to $2.0 \%$ of the total burden for females (7).

Worldwide 1.9 million Deaths are attributed to physical inactivity. At least $60 \%$ of the global population does not achieve the minimum recommendation of 30 minutes of moderate physical activity daily (8).

Physical inactivity is a major contributor to overweight and obesity, which increases the risk of serious health consequences such as cardiovascular disease, Diabetes and others Breast, colon and endometrial cancers (9).

However, little is known about the magnitude of hypertension, smoking, physical inactivity and Alcohol consumption among adults around Gilgel Gibe Field Research centre of Jimma University, Southwest Ethiopia. Thus, this study aimed to determine the prevalence of the selected noncommunicable disease risk factors among adults at Gilgel Gibe Field Research Centre of Jimma University, Southwest Ethiopia.

\section{Methods}

This population-based cross-sectional survey of risk factors for CNCDs was conducted from September 2008 to January 2009 at Gilgel Gibe Field Research Center (GGFRC) of Jimma University. This study was part of the survey for determination of magnitude of CNCDs, risk factors of CNCDs and biochemical, immunological and hematological value determination for the community at GGFRC.

Individuals' aged 15 to 64 years from both sexes, who were residents of the 10 kebeles under surveillance by the research center were studied. The sample size was determined based on the WHO STEPS guideline which has three steps for stepwise assessment of risk factors for CNCDs. Step one, two and three were used to assess the risk factors through interviewing, physical measurement and biochemical tests, respectively. The population was stratified by sex, age (15-24 years, 25-34 years, 35-44 years, 45-54 years and 55-64 years) and residential area (urban and rural) and such stratification was considered in the sample size calculation so as to be able to make analysis by those variables. For step one (interview) and two (physical measurement), 250 individuals from each sex and each age stratum were taken giving a sample size of 2500 . However, due to further stratification by residential area, the sample size was doubled to 5,000. Taking $10 \%$ non-response rate, the total sample size became 5,500. The sample was allotted to each age, sex and residential area stratum proportional to its size. Individual study participants were then selected from each stratum by stratified random sampling. Data of 4273 adults were extracted for analysis after excluding Variables with Incomplete data.

The data were cleaned and analysed by using SPSS for windows version 15.0. Blood pressure was categorized to hypertensive and not hypertensive based on WHO cut off point for systolic blood pressure (SBP $>=140 \mathrm{~mm} \mathrm{Hg}$ ) and diastolic pressure $(\mathrm{DBP}>=90 \mathrm{~mm} \mathrm{Hg})$. The level of total physical activity was computed according to world health organization Physical activity analysis guideline. Descriptive analysis was performed to know magnitudes of these risk factors. Finally, multivariable logistic regression with enter method was used to identify risk factors for hypertension. Statistical significance was declared at $\mathrm{p}<0.05$ to $95 \%$ of CI.

The proposal was presented to Medical Sciences Faculty research committee and the project owners and submitted to the University's Research and Publication Office for final ethical clearance. Permission was secured from the Gelgel gibe survey data owners.

\section{Results}

\subsection{Socio -demographic Characteristics of Study Subjects}

Table 1. Socio demographic characteristics of study subjects among adults at GGFRC, 2010.

\begin{tabular}{|c|c|c|c|}
\hline Variables & & Number & Percentage \\
\hline \multirow{2}{*}{ Sex } & Male & 2030 & 47.5 \\
\hline & Female & 2247 & 52.5 \\
\hline \multirow{5}{*}{ Age category } & $15-24$ & 720 & 17.0 \\
\hline & $25-34$ & 870 & 20.7 \\
\hline & $35-44$ & 921 & 21.9 \\
\hline & $45-54$ & 865 & 20.5 \\
\hline & $55-64$ & 837 & 19.9 \\
\hline \multirow{6}{*}{ Ethnicity } & Oromo & 3793 & 88.7 \\
\hline & Yem & 190 & 4.4 \\
\hline & Amhara & 137 & 3.2 \\
\hline & Gurage & 77 & 1.8 \\
\hline & Dawuro & 58 & 1.4 \\
\hline & Other & 21 & 0.5 \\
\hline \multirow{2}{*}{$\begin{array}{l}\text { Able to read and } \\
\text { write }\end{array}$} & Yes & 3070 & 71.9 \\
\hline & No & 1197 & 28.1 \\
\hline \multirow{2}{*}{ Attend formal school } & Yes & 1081 & 91.2 \\
\hline & No & 104 & 8.8 \\
\hline \multirow{3}{*}{$\begin{array}{l}\text { Highest grade } \\
\text { completed }\end{array}$} & Primary school & 604 & 55.9 \\
\hline & Secondary school & 436 & 40.3 \\
\hline & College and above & 41 & 3.8 \\
\hline \multirow{10}{*}{ Occupation status } & Farmer & 1881 & 44.0 \\
\hline & Housewives & 1470 & 34.4 \\
\hline & Students & 246 & 5.7 \\
\hline & Merchant & 224 & 5.2 \\
\hline & Civil servant & 136 & 3.2 \\
\hline & Daily labour & 122 & 2.9 \\
\hline & Unemployed & 86 & 2.0 \\
\hline & NGO & 67 & 1.6 \\
\hline & Other & 35 & 0.8 \\
\hline & Refused & 6 & 0.1 \\
\hline
\end{tabular}


Data from $4277(85.5 \%)$ study subjects were included in the analysis. Of these, about $2247(52.5 \%)$ were females and $2030(47.5 \%)$ were males. Mean age of the study participants was 39 years $(\mathrm{SD}=14)$. Of those able to read and write, about $1081(91.2 \%)$ attended formal education and the median duration of schooling was 6 years. About $1881(44.0 \%)$ of study subjects were farmers in occupational status (Table 1).

\subsection{Prevalence of Behavioural Risk Factors}

Tobacco consumption

The prevalence of smoking among the respondents was $397(9.4 \%)$. The proportion of male smokers was significantly higher than female smokers (X2 $=397.6 \mathrm{df} 1$, $\mathrm{p}<0.001)$. The mean age of starting daily smoking was 23 $(\mathrm{SD}=12.2)$ for both sexes. Regarding age \& sex specific smoking rate, it is noticed that smoking is more prevalent among males aged 45-54. Regarding types of tobacco products smoked about 193(48.2\%), 151(38\%) of current smokers smoke hand rolled type and factory tobacco respectively (Table 2 ).

Table 2. Distribution of tobacco consumption among adults at GGFRC by age groups and sexes, Jimma, Southwest Ethiopia, 2010.

\begin{tabular}{lllllll}
\hline \multirow{2}{*}{$\begin{array}{l}\text { Age } \\
\text { group }\end{array}$} & Female & \multicolumn{3}{c}{ Male } & \multicolumn{3}{c}{ Total } \\
\cline { 2 - 7 } & $\mathbf{N}$ & Freq (\%) & $\mathbf{N}$ & Freq (\%) & N & Freq (\%) \\
\hline $15-24$ & 363 & $2(0.6)$ & 357 & $31(8.7)$ & 720 & $33(4.6)$ \\
$25-34$ & 475 & $2(0.4)$ & 395 & $68(17.2)$ & 870 & $70(8.0)$ \\
$35-44$ & 474 & $4(0.8)$ & 447 & $102(22.8)$ & 921 & $106(11.5)$ \\
$45-54$ & 442 & $6(1.4)$ & 423 & $109(25.8)$ & 865 & $115(13.5)$ \\
$55-64$ & 450 & $6(1.3)$ & 387 & $67(17.3)$ & 837 & $73(8.7)$ \\
Total & 2204 & $20(0.9)$ & 2009 & $377(18.8)$ & 4213 & $397(9.4)$ \\
\hline
\end{tabular}

\subsection{Alcohol Consumption}

The prevalence of alcohol consumption was about $299(7.0 \%)$ of this about $171(8.5 \%)$ were male and $128(5.8 \%$ were female. Concerning age specific rate, $76(8.8 \%)$ drinkers were in the age group 45-54 years. The proportion of the male drinking daily was higher than female $20(11.9 \%)$ vs. 3 (2.4\%) (Table 3).

Table 3. Distribution alcohol consumption among adults at Gelgel Gibe field research centre, 2010.

\begin{tabular}{lllllll}
\hline \multirow{2}{*}{$\begin{array}{l}\text { Age } \\
\text { group }\end{array}$} & \multicolumn{1}{c}{ Female } & \multicolumn{3}{c}{ Male } & \multicolumn{2}{c}{ Both sexes } \\
\cline { 2 - 7 } & $\mathbf{N}$ & Freq (\%) & $\mathbf{N}$ & Freq (\%) & $\mathbf{N}$ & $\begin{array}{l}\text { Freq } \\
(\%)\end{array}$ \\
\hline $15-24$ & 363 & $17(4.7)$ & 356 & $16(4.5)$ & 719 & $33(4.6)$ \\
$25-34$ & 473 & $30(6.3)$ & 395 & $29(7.3)$ & 868 & $59(6.8)$ \\
$35-44$ & 473 & $34(7.2)$ & 446 & $37(8.3)$ & 919 & $71(7.7)$ \\
$45-54$ & 442 & $23(5.2)$ & 422 & $53(12.6)$ & 864 & $76(8.8)$ \\
$55-64$ & 449 & $24(5.3)$ & 386 & $36(9.3)$ & 835 & $60(7.2)$ \\
Total & 2200 & $128(5.8)$ & 2005 & $171(8.5)$ & 4205 & $299(7.0)$ \\
\hline
\end{tabular}

\subsection{Level of Total Physical Activity}

About $76.8 \%$ (95\%CI: 75.5, 78.1) of the respondents practiced vigorous (high) activity; about $14.2 \%$ (95\%CI: 13.1 , $15.3)$ and $9.0 \%(95 \% \mathrm{CI}: 7.2,9.9)$ practiced moderate and low physical activity respectively. On the other hand, significantly more females $(12.6 \%)$ than males $(5.3 \%)$ were classified as having low levels of TPA (X2 135, P $<0.001$ (Table 4). The average total physical activity (TPA, in METminutes per week) was estimated to be 14143 in males and 7928 in females.

Table 4. Distribution level of total physical activity among adults at GGFRC by sex, 2010.

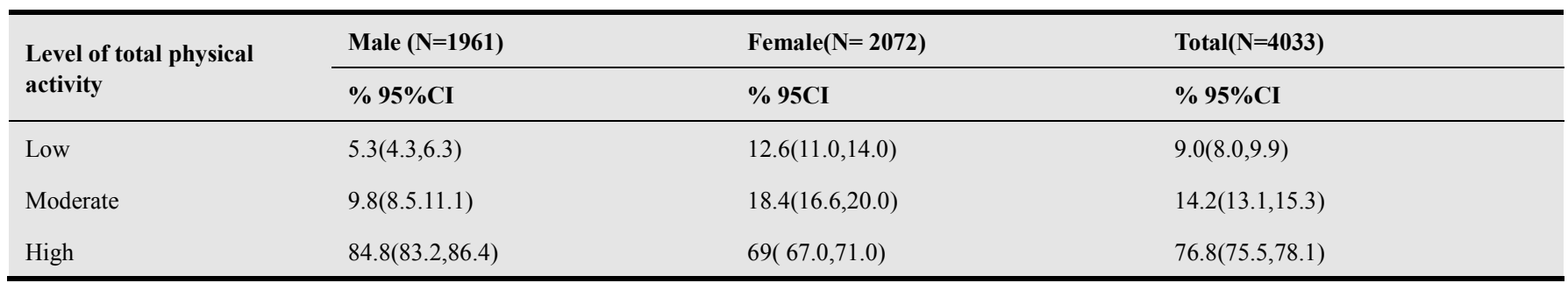

\subsection{Hypertension}

Prevalence of hypertension based on blood pressure measurement was $82(3.2 \%)$ while based on self report it was about 109 (2.6\%) (Table 5). The prevalence of systolic hypertension $(\geq 140 \mathrm{~mm} \mathrm{Hg}$ ) was $6.1 \%$ and it was higher among females compared to males $(6.7 \%$ vs. $5.5 \%)$. Five percent of respondents were having diastolic $(\geq 90 \mathrm{~mm} \mathrm{Hg})$ hypertension. There was no significant difference in hypertension between male and female ( $p$-value $>0.05$ ).
Table 5. Prevalence of hypertension based on blood pressure measurement and self report among adults at Gilgel Gibe field research center, 2010.

\begin{tabular}{|c|c|c|c|c|}
\hline \multirow{2}{*}{$\begin{array}{l}\text { Hypertensive status } \\
\text { of respondents }\end{array}$} & \multicolumn{2}{|c|}{$\begin{array}{l}\text { Based on BP } \\
\text { measurement }\end{array}$} & \multicolumn{2}{|c|}{ Based on self repor } \\
\hline & Frequency & $\%$ & Frequency & $\%$ \\
\hline Hypertensive & 82 & 3.2 & 109 & 2.6 \\
\hline Not Hypertensive & 2465 & 96.8 & 4156 & 97.4 \\
\hline Total & 2547 & 100.0 & 4266 & 100.0 \\
\hline
\end{tabular}

Hypertension was statistically significantly higher among 
respondents in the age categories 25 and above $(25-34, \mathrm{OR}=$ $3.86,95 \% \mathrm{CI}(1.15,13.02) ; 35-44, \mathrm{OR}=4.86,95 \% \mathrm{CI}(1.38$, $17.13) ; 45-54, \mathrm{OR}=8.62,95 \% \mathrm{CI}(2.28,32.55) ; 55-64, \mathrm{OR}=$ $15.84,95 \%$ CI $(3.71,67.64)$ compared to those $15-24$ years. Respondents at college and above were more likely to have hypertension compared to those at primary level $(\mathrm{OR}=7.03$ (95\%CI: 2.12, 23.26) (Table 6).

Table 6. Multivariable analysis for hypertension based on BP measurement among adults at Gelgel Gibe Field research centre, 2010.

\begin{tabular}{lll}
\hline Variable & $\begin{array}{l}\text { Crude Odds ratio } \\
(\mathbf{9 5 \%} \text { CI) }\end{array}$ & $\begin{array}{l}\text { Adjusted Odds Ratio } \\
(\mathbf{9 5 \%} \text { CI) }\end{array}$ \\
\hline Sex & & \\
Female & $0.70(0.48,1.04)$ & $1.40(0.64,3.06)$ \\
Male & 1 & 1 \\
Physical activity & & \\
Low & 1 & 1 \\
Moderate & $1.49(0.72,3.04)$ & $1.05(0.26,4.21)$ \\
High & $0.72(0.37,1.38)$ & $0.73(0.20,2.63)$ \\
Education & & \\
Primary & 1 & 1 \\
Secondary & $2.50(1.21,5.12)^{*}$ & $4.13(1.79,9.51)^{*}$ \\
College & $6.80(2.29,20.47)^{*}$ & $7.03(2.12,23.26)^{*}$ \\
Alcohol intake & & \\
No & 1 & 1 \\
Yes & $1.98(1.12,3.52)$ & $1.15(0.48,2.73)$ \\
Age Category & & 1 \\
$15-24$ & 1 & $3.86(1.15,13.02)^{*}$ \\
$25-34$ & $1.67(0.67,4.16)$ & $4.86(1.38,17.13)^{*}$ \\
$35-44$ & $2.15(0.89,5.14)$ & $8.62(2.28,32.55)^{*}$ \\
$45-54$ & $3.68(1.61,8.43)^{*}$ & $15.84(3.71,67.64)^{*}$ \\
$55-64$ & $4.98(2.21,11.20)^{*}$ &
\end{tabular}

*Indicates $\mathrm{p}$ value less than $5 \%$

\section{Discussion}

Developing countries have been experiencing a shift in disease type and prevalence, generally referred to as the epidemiologic transition. Infectious diseases, once dominant in Low income countries are now being replaced by noncommunicable diseases (NCDs), which include cardiovascular disease (CVD), hypertension, diabetes, overweight and obesity, osteoporosis, and some types of cancer (11).

Most of these non communicable diseases share common risk factors like tobacco use, alcohol intake, physical inactivity and obesity (12) .This study revealed that the prevalence of smoking was $9.4 \%$, which is higher than the prevalence of smokers among adults in Butajira, southern Ethiopia which was $5.8 \%$ (13). A study conducted among adult population in North East, Nigeria indicated that the prevalence of smoking was higher in male than female (14) and this is consistent with finding in this study.

The prevalence of alcohol consumption in this study was about $7.0 \%$, which is higher than that reported in a free living urban population of India (15) and lower than $17.5 \%$ reported from Nigeria (16). Different studies reported that the prevalence of alcohol consumption is more frequent among males than female $(15,4)$ which is consistent with our observation in this study.

A Study conducted in Nauru district indicated that consumption of alcohol was higher among men in the age group 45-54 years (41.7\%) and female in the age range of 15$24(29 \%)$ (17). Our finding also shows the prevalence of alcohol consumption was higher among men 45-54 years of age; which is higher than women. This may be due to the difference in lifestyle as men compared to women usually go out for recreation and have better opportunity to drink alcohol

This study showed that the average total physical activity (TPA, in MET-minutes per week) was estimated to be 14143 in males and 7928 in females. A study conducted among adults in Addis Ababa revealed that the average total physical activity (TPA, in MET-minutes per week) was estimated to be 7967 in males and 4709 in females (18). The difference in levels of total physical activity may be due to that the respondents involved in this study were rural by residence and most of them were farmers.

The same study indicated that significantly more females $(31.2 \%)$ than males $(16.9 \%)$ were classified as having low levels of TPA (18), which was consistent with the finding in this study. This study revealed that the prevalence of hypertension based on blood pressure measurement was 3.2\% and it was relatively lower than reports from different studies $(19-23)$. The self reported hypertension however was lower $(2.6 \%)$ than the measured. A study conducted in rural Maharashtra indicated that the prevalence of hypertension was $7.24 \%$, in which higher prevalence appeared in females than males (19). Mumbai reported 7.82\% (6.1\% and $10.5 \%$ in male and female respectively) (20) and another Study from Sevagram reported $3.41 \%$ in rural population in which $2.9 \%$ was in male and $4.6 \%$ in female (21). In contrast to this, a study conducted in the Mekong Delta region of Vietnam revealed the prevalence of hypertension was higher in men than women (22). But our study indicated that there was no significant difference in hypertension between males and females. Differences in age of the study subjects, sample size, residence and lifestyle may contribute to low level of hypertension in this study. Our study showed that hypertension increases with age which is consistent with reports from other studies $(18,22)$.

This study revealed that sex, physical activity, alcohol intake was not statistically significantly associated with hypertension. A study from Population-Based Study in Pelotas also indicated that sex and physical activity were not statistically significantly associated with hypertension, but alcohol consumption was found to be significantly associated with hypertension (24). This may be due to differences in type and content of alcohol consumed by the study subjects.

\section{Strength and Limitation of the Study}

This study was used the WHO STEP survey after contextualizing to the local area as the strength. As limitation, the biochemical data were not included in the analysis for 
this particular paper.

\section{Conclusion and Recommendations}

The prevalence of NCD Risk factors among the study subjects was high. These findings are crucial for evidence based decision making. This study will also give baseline information that will enable researchers to conduct further studies.

\section{Acknowledgments}

I extend my grateful appreciation for experts of the field research center; who encouraged me to conduct this recently hot issue on prevention and control of CNCDs including HTN at GGFRC \& delivering all relevant materials that were helped to us during work. The study was funded by Jimma University, College of Public Health and Medical Science.

\section{References}

[1] World Health Organization. Diet, Nutrition and the prevention of Chronic Diseases. In Technical report Series 916 Geneva, World Health Organization; 2003

[2] Patricia M, Megan W, Kristi R, Paul M, Paul K, Jiang H. Global burden of hypertension: Analysis of worldwide data. Lancet 2005; 365: 217-223.

[3] Opie LH, Seedat YK. Hypertension in Sub-Saharan African populations. Circulation 2005; 112(23):3562-3568.

[4] Tesfaye F. Epidemiology of cardiovascular disease risk factors in Ethiopia: the rural-urban gradient. J Hum Hypertension 2007; 21(2):28-37.

[5] World Health Organization. The world health report: Reducing risk, Promoting Healthy Life, Geneva. WHO 2002.

[6] World Health Organization. Global Status Report on Alcohol. Geneva, Switzerland, World Health Organization, 2004

[7] Rehm J et al. Alcohol use. In: Global and Regional Burden of Diseases Attributed to Selected Major Risk Factors. Geneva, Switzerland, World Health Organization, 2004; 959-1108.

[8] World Health Organization. World Health Report 2002: Reducing risks, promoting healthy life. Geneva, Switzerland, World Health Organization, 2002

[9] World Health Organization. Preventing chronic diseases: A vital investment. Geneva, Switzerland, World Health Organization, 2005

[10] Muluneh AT, Hailemichael A, Tessema F, Alemseged F, Woldemichael K, Asefa M etal. Population based survey of chronic non Communicable Diseases at Gilgel Gibe Field Research center, Southwest Ethiopa. Ethiop J Health Sci 2012; 22(5):7-18.
[11] Strong K, Mathers C, Leeder S, Beaglehole R. Preventing chronic diseases: how many lives can we save? The Lancet 2005; 366:1578-1582.

[12] World Health Organization, Regional Office of South East Asia. Strengthening Partnerships for Integrated Prevention and Control of Non communicable Diseases: a SEANET-NCD Meeting Chandigarh, India. 15-19 June 2009.

[13] Neil's Schoenmaker, Jeroen Hermanides,Gail Davey: Prevalence and predictors of smoking in Butajira town, Ethiopia, Ethiop J Health Dev 2005; 19(3):182-187.

[14] O. Desalu, A Olokoba, A Danburam, F Sawalu , B Issa. Epidemiology of Tobacco Smoking among adults population in North-East Nigeria. The International Journal of Epidemiology 2007; 6(1).

[15] Mehan MB, Surabhi S, Solanki GT. Risk factor profile of noncommunicable diseases among middle-income (18-65 years) free-living urban population of India. Int J Diab Dev Ctries 2006; 26:169-76.

[16] Gabriel Uche Pascal Iloh, Abali Chuku, Nnadozie Paul Obiegbu, John Nnaemeka Ofoedu, Augustin Obiora Ikwudinma. Frequency of Cardiovascular Risk Factors in Adult Nigerians with Family History of Non-Communicable Cardiovascular Disease in a Primary Care Clinic of a Tertiary Hospital in a Resource-Constrained Environment of Eastern Nigeria. American Journal of Health Research. Vol. 1, No. 1, 2013, pp. 17-25.

[17] The Nauru NCD Risk Factors STEPS Report collaboration from the Nauru Ministry of Health, the World Health Organization and the Centre for Physical Activity and Health, University of Sydney, 2004

[18] F. Tesfaye, P Bypass, S. Wall. Population based prevalence of high blood pressure among adults in Addis Ababa: uncovering a silent epidemic. BMC Cardiovascular Disorders 2009; 9:39.

[19] Todkar SS, Guajarathi W, Tapare VS. Period prevalence and socio demographic factors of hypertension in rural Maharashtra. Indian J community Med. 2009; 34(3):183-7

[20] Joshi V, Patel C, Dhar L. Prevalence of hypertension in Mumbai. Indian J Med Sci 2000; 54:380-3

[21] Jajoo N, Kalantri P,Gupta P,Jain P,Gupta K. Prevalence of hypertension in rural population around sevagram. MGM, Wardha. JAPI 1993;41:422-4

[22] Luc H Pham, Thuy B Au1, Leigh Blizzard, Nhan B Truong, Michael D Schmidt, Robert et al. Prevalence of risk factors for non-communicable diseases in the Mekong Delta, Vietnam: results from a STEPS survey. BMC Public Health 2009; 9:291

[23] Gary Hon-chung Ho, Anne Kate Press, Christine Bumatay Sethna The Prevalence of Hypertension and Associated Risk Factors in a Latino Subgroup: A Rural Batey Population in the Dominican Republic. Science Journal of Public Health. Vol. 2, No. 5, 2014, pp. 480-485.

[24] Costa, Franklin Correa Barcellos, Marcelo Leal Sclowitz et al. Hypertension Prevalence and its Associated Risk Factors in Adults: A population based survey in Pelotas. Arq Bras Cardiol 2007; 88(1) : 54-59. 